УДК 633.368(575.2)

ПРОДУКТИВНОСТЬ СОРТОВ АРАХИСА (ARACНIS HYPOGAЕА L.) В ЧУЙСКОЙ ДОЛИНЕ КЫРГЫЗСКОЙ РЕСПУБЛИКИ

\author{
Асаналиев А.Ж.
}

Кыргызский национальный аграрный университет им. К.И. Скрябина, Бишкек, e-mail: asanaly61@mail.ru

\begin{abstract}
В Кыргызской Республике в период 1991-2016 гг. площади посевов зерновых бобовых значительно выросли. Это произошло за счет расширения посевов фасоли. В официальной государственной статистике учет ведется под строкой зернобобовые (в весе после доработки). Поэтому значение других бобовых культур, кроме фасоли, остается в тени. Хотя посевные площади арахиса, нута и гороха постепенно увеличиваются. Они еще не имеют статус коммерческих культур в масштабе государства, но имеют экономическое значение в домохозяйствах многих фермеров. Почвенно-климатические условия с горным ландшафтом Кыргызской Республики схожи с родиной происхождения этой культуры и позволяют получить высокий урожай зерна apaхиса. Фермеры выращивают сорта народной селекции, которые имеют относительно низкий урожай зерна. Нами были получены сорта из iCrisAT (international Crop research institute for semi-Arid Tropics) и изучена фенология развития интродуцированных сортов, проведено сравнение морфометрических характеристик, установлена продуктивность и даны рекомендации для возделывания выделившихся сортов. Укорачивание высоты цветоносного побега у растений снижает количество гинофор, закладываемых ниже середины побега. Чем выше побег, тем больше на нем гинофор и сформировавшихся бобов арахиса. Между высотой стебля и урожайностью зерна обнаружена прямая положительная зависимость, которая подтверждена в корреляционно-регрессионным анализом $(\mathrm{r}=0,800 ; \mathrm{y}=58+0,7 \mathrm{x})$. Между выходом зерна из бобов и урожайностью бобов существует тесная корреляция $(\mathrm{r}=0,760)$. Уровень взаимосвязи между двумя индикаторами определяется уравнением регрессии у $=62,8+0,24$ х. Наши наблюдения показали, что из испытанных сортов максимальную продуктивность показали два сорта зарубежной селекции, iCgV 95290 и iCgV 95322 , которые дали прибавку урожая зерна 193 и 172 кг/га соответственно по сравнению со стандартным сортом Кыргызский местный.
\end{abstract}

Ключевые слова: арахис, сорт, урожайность, зерно

\title{
PRODUCTIVITY OF GROUNDNUT (ARACHIS HYPOGAEA L.) VARIETIES IN CHUI VALLEY OF THE KYRGYZ REPUBLIC
}

\author{
Asanaliev A.Zh.
}

Kyrgyz National Agrarian University named after K.I. Skryabin, Bishkek, e-mail: asanaly61@mail.ru

\begin{abstract}
Arable land under legume crops in Kyrgyz Republic growing up greatly due to expansion of kidney beans plantations in period 1991-2016. Only grain legumes listed in official statistic state. That is why the importance of other legume crops are not pointed except bean. Meantime, groundnut, chick-pea and pea sowing lands are gradually growing up. But they do not have commercial status under the state scale. However, these crops have already main economic role in many household farms. Soil and climate conditions of mountain landscape of Kyrgyz Republic are similar with origin place of this crop and able to provide high yield of groundnut. Farmers grow varieties of folk breeding, which have a relatively low grain yield. The varieties from ICRISAT (International Crop Research Institute for Semi-Arid Tropics) were received, and phenology development of introduced varieties was made, comparative research of morphology characteristics was conducted, varieties productivity was identified and recommendation for cultivation of selected varieties was made. I was found out that shortening of plant generative stem decreases the gynophores number placed below of central part of the stem. The higher the stem the more gynophores and the formed peanut beans. Direct positive dependence between stem heights and grain yields was found, which was studied in the correlation-regression analysis $(r=0,800 ; y=58+0,7 x)$. Between shelter percentages and grain yields close correlation exists $r=0,760$. Level of inter correlation between two indicators determines by regression equalization $\mathrm{y}=62,8+0,24 \mathrm{x}$. The observation shows that maximum productivity of tested varieties has two varieties of foreign breeding - ICGV 95290 and ICGV 95322, which have addition yield +193 and $+172 \mathrm{~kg} / \mathrm{ha}$ in comparative with standard variety Kyrgyzskiy mestny, correspondingly.
\end{abstract}

Kewwords: groundnut, variety, yield, grain

По данным FAO UN (Продовольственная и сельскохозяйственная организация Организации Объединённых Наций) в мире арахис (земляной орех) выращивается на площади 26,5 млн га, валовое производство его составляет около 43,9 млн тонн, средняя продуктивность 1,65 тонн/га [1].

Арахис - шестая из очень важных масличных культур в мире. Он содержит 48$50 \%$ масла и $26-28 \%$ белка, и он богатый источник жира, минералов и витаминов. Свыше 100 стран в мире его выращивают. Развивающиеся страны занимают 97\% мировых посевных площадей и $94 \%$ мирового валового производства. Производство арахиса сосредоточено в Азии и Африке $(56 \%$ и $40 \%$ посевных площадей и $68 \%$ и $25 \%$ мирового производства соответственно) [2].

Культивируемый арахис (Arachis hypogaea L.) принадлежит к роду Arachis в суб- 
трибе Stylosanthinae трибы Aeschynomenea семейства Leguminosae. Это самоопыляющееся, тропическое однолетнее бобовое растение. В зависимости от места расположения встречается и перекрестное опыление от 1 до 10\% преимущественно пчелами из рода Apis, Bombus [3].

Яркие желтые обоеполые цветки арахиса расположены в соцветии, похожем на колос, в пазухах листьев. Первые цветки появляются на 4 и 6 неделе после посева, и максимальное цветение продолжается от 6 до 10 недель после посева. От 8 до 14 дней после опыления воздушный женский крючковатый орган внедряется в почву и принимает горизонтальное расположение до созревания в бобиках. Арахис обычно созревает максимум за 100-150 дней в зависимости от сорта [4].

Главными штатами выращивания арахиса в Индии являются Chhabra и Kamra, где распространена засоленность около 2 млн га. На основе двух сезонных испытаний определены 11 генотипов: NRCG 2588, 4659, 5513, 6131, 6450, 6820, 6919, 7206, TMV 2 NLM, TG 33, JNDS-2004-15, которые характеризовались высоким стоянием растений и урожайностью семян более чем 50 г/м м $^{2} 10$ генотипов: JNDS-2004-1, JNDS-2004-3, JNDS-2004-16, TG 28, TG 38C, TG 42, PBS 30031, PBS 30033, NRCG 6155, ICGV 86031 были с урожайностью

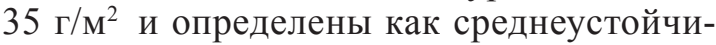
вы к засоленности для средней степени засоления [5].

В Бангладеше изучали два сорта Dhaka-1 (Испанский тип, эректоидный) и DG-2 (Виргинский тип, стелющийся), в местных условиях установлено расстояние в междурядьях и между растениями в рядке для различных агроэкологических районов. Установлено, что сорта с различным порядком роста требуют различных схем посева чтобы обеспечить их урожайный потенциал, сорт Dhaka-1 требует близкого расстояния 20x10 см, в то время как DG-2 требует широкого размещения 40×20 см чтобы произвести максимальный урожай [6].

В Нигерии установили, что по своим параметрам роста сорт SAMNUT-22 превышает SAMNUT-23. По данным Бала и соавт. сорт SAMNUT-22 рекомендуется сеять в середине июня при внесении удобрений $\mathrm{N}_{20}+\mathrm{P}_{26}+\mathrm{K}_{26}$ на 1 га для получения хорошего урожая [7].

В США сорта Florida MDR98 и Southern Runner очень чувствительны к холодным температурам, сорта Georgia Green и SunOleic 97R были относительно устойчивы к пониженным температурам. Отмеченные данные позволяют оценить генетическое разнообразие сортообразцов, правильно подобрать сорта там, где отмечены холодные температуры в период сева, и увеличить производство арахиса [8].

В Кыргызстане площади посева арахиса пока незначительные, в официальной статистике его площади включаются под тему зерновые бобовые. Между тем уже многие фермеры в южной части страны и даже в Чуйской долине выращивают арахис и получают хорошие доходы. Научные исследования по разработке технологии его возделывания не проводились. Фермеры нуждаются в семенах высокопродуктивных сортов.

Цель исследований - интродукция сортов, на основе которых можно получить высокие и устойчивые урожаи белкового зерна, способствующие продовольственной безопасности и питанию людей. В задачу исследования входило изучение фенологии развития интродуцированных сортов, сравнение их морфометрических характеристик, а также отбор выделившихся высокоурожайных сортов.

\section{Материалы и методы исследования}

Полевые исследования проводились в 20002002 гг. на полях крестьянского хозяйства «Дыйкан». Предшественник - озимая пшеница (сорт Интенсивная). Объектом исследований были сорта из ICRISAT (International Crop Research Institute for Semi-Arid Tropics - Международный исследовательский институт растениеводства для полузасушливых тропиков) и контрольный сорт Кыргызский местный. Междурядье 70 см. Учетная площадь делянок 105 м $^{2}$ (7 м×15 м). Размещение делянок рендомизированное в четырехкратной повторности. Срок посева 1 мая. Учет урожая проводился поделяночно, взвешиванием урожая бобов, а не отделенного зерна согласно методике ICRISAT.

Опыты были заложены на северных обыкновенных сероземах на высоте 900 м над уровнем моря на том же массиве, где были заложены опытные участки по полевым культурам опыты. Почва опытного участка не засолена. Почва имела слабощелочную реакцию, $\mathrm{pH}$ от 7,5 до 8,0.В пахотном слое содержание гумуса варьировало от 2,5 до 2,7\%, а в подпахотном слое от 0,7 до $1,3 \%$. Количество валового азота составляло 0,10-0,18\%, фосфора 0,12-0,28\%, калия 2,4-3,3\%. По содержанию подвижных форм фосфора и калия почва относится к среднеобеспеченным. Легко усвояемых фосфатов содержалось в пахотном слое 2,8-3,9 мг на 100 г почвы, обменного калия 12-26 мг [9].

В 2000 г. по данным метеорологической службы Кыргызской Республики годовая сумма осадков было 441 мм. Из них в период активного роста и развития растений арахиса в июне 14,5 мм, в июле 8,0 мм, в августе 14,6 и в сентябре 56,0 мм. 
Таблица 1

Морфометрические и продуктивные показатели сортов арахиса, среднее за 2000-2002 гг.

\begin{tabular}{|c|c|c|c|c|c|c|}
\hline № & Сорта & Тип & $\begin{array}{c}\text { Окраска } \\
\text { зерна }\end{array}$ & $\begin{array}{c}\text { Выход зерна } \\
\text { (масса без боба), } \%\end{array}$ & $\begin{array}{c}\text { Масса } \\
1000 \text { семян, г }\end{array}$ & $\begin{array}{c}\text { Высота стебля } \\
\text { перед уборкой, см }\end{array}$ \\
\hline 1 & ICGV 94299 & Spanish & Красная & 64,67 & 315,00 & 67,37 \\
\hline 2 & ICGV 94341 & Spanish & Красная & 64,40 & 304,67 & 65,70 \\
\hline 3 & ICGV 94350 & Spanish & Красная & 65,90 & 330,67 & 64,23 \\
\hline 4 & ICGV 94357 & Spanish & Красная & 65,40 & 329,00 & 65,90 \\
\hline 5 & ICGV 94358 & Spanish & Красная & 64,83 & 332,33 & 66,27 \\
\hline 6 & ICGV 95244 & Spanish & Красная & 65,63 & 321,67 & 66,77 \\
\hline 7 & ICGV 95245 & Spanish & Красная & 65,10 & 338,67 & 65,90 \\
\hline 8 & ICGV 95248 & Spanish & Красная & 66,40 & 489,33 & 67,30 \\
\hline 9 & ICGV 95271 & Spanish & Красная & 64,77 & 324,67 & 64,53 \\
\hline 10 & ICGV 95278 & Spanish & Красная & 66,40 & 393,00 & 68,33 \\
\hline 11 & ICGV 95290 & Spanish & Красная & 67,53 & 448,33 & 70,93 \\
\hline 12 & ICGV 95299 & Spanish & Красная & 66,33 & 321,33 & 64,52 \\
\hline 13 & ICGV 95319 & Spanish & Красная & 66,03 & 329,67 & 66,43 \\
\hline 14 & ICGV 95322 & Spanish & Красная & 68,07 & 461,00 & 76,57 \\
\hline 15 & Сhiсо & Spanish & Желтая & 68,27 & 333,33 & 66,87 \\
\hline 16 & Кыргызский & Spanish & Желтая & 68,63 & 448,33 & 76,27 \\
\hline & местный & & & 66,14 & 363,81 & 71,95 \\
\hline
\end{tabular}

В 2001 г. годовая сумма осадков была 443 мм. Из них в период активного роста растений соответственно в июне 6,0 мм, в июле 48,6 мм, в августе 20,7 и сентябре 6,9 мм.

В 2002 г. это было 752,5 мм. Из них в период активного роста растений соответственно в июне 86,3 мм, в июле 34,7 мм, в августе 12,7 и сентябре 16,5 мм.

Исходя из данных об осадках, можно утверждать, что в период образования, формирования и налива бобиков (июль - сентябрь) благоприятные годы для растений арахиса были 2000 и 2001 гг. Также по данным метеорологической службы амплитуда колебания между максимальной (дневной) и минимальной (ночной) месячной температурами в период май октябрь 2001 г. был наиболее благоприятный. Этот показатель в среднем за эти шесть месяцев в 2000 г. $26,8^{\circ} \mathrm{C}, 2001$ г. $26,7^{\circ} \mathrm{C}$ и 2002 г. $27,7^{\circ} \mathrm{C}$. Большая амплитуда колебания температуры воздуха в течение сутки отрицательно влияет на биологические процессы, происходящие в организме растений.

\section{Результаты исследования и их обсуждение}

Для науки и производства очень важно знать соотношение показателей продуктивности земляного ореха. В этой связи мы проводили учет выхода зерна из бобов, массы 1000 зерен и высоты стебля перед уборкой.

Данные табл. 1 показывают, что испытуемые сорта разные по степени роста и продуктивности. Так, по высоте стебля многие испытуемые сорта отставали от местного сорта. Только один сорт ICGV 95322 превысил данные контрольного сорта.
Уменьшение высоты цветоносного побега указывает на снижение количества гинофор, формируемых ниже середины побега. Чем выше высота побега, тем больше количество гинофор, больше формируется цветков на стебле и, соответственно, выше продуктивность арахиса. Так, у сортов ICGV 95271, ICGV 94350 высота стебля соответственно меньше на 12,04-11,74 cм, чем у контрольного сорта. Это приведет к снижению количества цветков и гинофор. Отклонение от среднего составляет от 1,02 до 12,04 см (рис. 1).

Между высотой стебля и урожайностью зерна обнаружена прямая положительная зависимость, которая найдена нами в корреляционно-регрессионном анализе $(\mathrm{r}=0,800 ; \mathrm{y}=58+0,7 \mathrm{x})$.

Плоды арахиса, формой своей напоминающие шелковичный кокон, вызревают под землей (подобно клубням картофеля), отчего их называют еще земляными орехами. Внутри кокона (боба) заключены семена (или орешки) различной формы и окраски: светло-розовые, светло- и темно-красные, иногда черно-фиолетовые [10].

Поэтому для потребления зерна для пищи необходимо извлечь зерно из боба. В этой связи для оценки сортов важно знать долю выхода зерна из боба. Как видно из данных табл. 2, в среднем около $34 \%$ массы плода составляет его оболочка. Не- 
сколько сортов имеют высокий выход зерна, это Кыргызский местный, Chico, ICGV 95322, ICGV 95290. Их индикаторы выхода зерна выше среднего показателя. Примечательно, что среднеранний сорт Chico оказался в этой группе сортов, совмещая скороспелость с хорошим выходом очищенного зерна (без боба). Скороспелость и большой выход зерна - хорошо сочетаемые хозяйственно полезные признаки. Вторая группа была представлена сортами относительно с высоким выходом чистого зерна: ICGV 95278, ICGV 95248, ICGV 95299, ICGV 95248 и другие. Tpeтья группа состояла из сортов, которые имели относительно низкий выход чистого зерна - ниже $65 \%$. К этой группе относятся следующие сорта: ICGV 94358 , ICGV 95271, ICGV 94341 и другие. Важность определения и знания выхода зерна в том, что уменьшение или повышение выхода зерна связано с реальным изменением чистого урожая зерна, т.е. после очистки зерна от бобов. Так, у сорта ICGV 94341 потери урожая за счет низкого выхода зерна по сравнению с контрольным сортом составляют 4,2\% (т.е. 25,4 кг/га). А у сорта ICGV 95290 за счет хорошего выхода зерна этот показатель составляет 1,4 кг с каждого га по сравнению с контрольным сортом. Статистический анализ показывает, что между выходом зерна и урожайностью существует тесная корреляция, выраженная $\mathrm{r}=0,760$. Диалектика уровня взаимосвязи между двумя индикаторами определяется уравнением регрессии у $=62,8+0,24 \mathrm{x}$.

Нами обнаружено, что многие позднеспелые сорта имеют меньший выход зерна. Очевидно, удлинение периода вегетации на

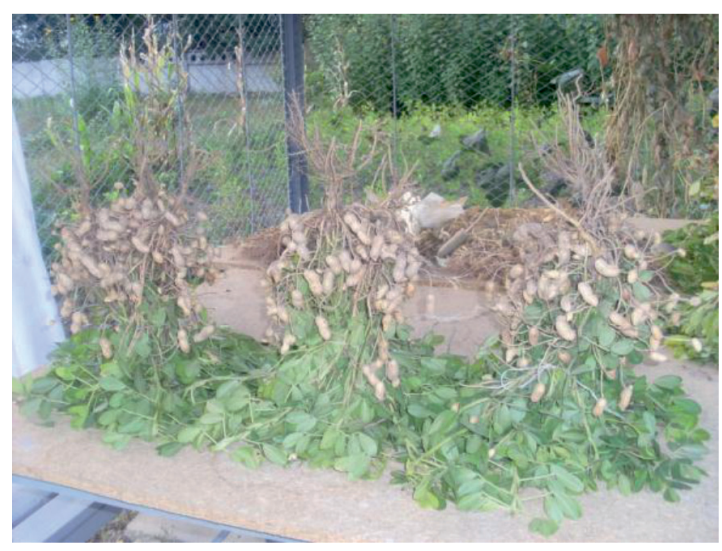

Puc. 1. Copma ICGV 95290, ICGV 95322 и Кыргызский местный (слева направо) поле приводит растения к не оптимальным условиям созревания и вызывает утолщение оболочки боба, которая защищает зерно от неблагоприятных условий.

Macca 1000 семян является одним из основных показателей в растениеводстве. Чем больше этот показатель, тем лучше заполнены питательными веществами зерна. Данные табл. 1 показывают, что из испытанных сортов ICGV 95248 и ICGV 95322 имеют наивысшую массу 1000 семян, а у сорта ICGV 95290 этот показатель равен контрольному сорту. Наши расчеты показали, что между массой 1000 семян и урожайностью существует тесная коррелятивная взаимосвязь, отраженная в $\mathrm{r}=0,790 ; \mathrm{y}=202,7+11,7$ x. Важно отметить, что испытуемые сорта, которые имели большой выход зерна, имели высокую массу 1000 зерен. Это относится к следующим сортам: ICGV 95322, ICGV 95248, Кыргызский местный, ICGV 95278, ICGV 95245.

Таким образом, анализ морфометрических и продуктивных индикаторов сортов показал, что по высоте стебля выделяются два сорта из международных питомников и Кыргызский местный. Четыре сорта (Кыргызский местный, Chico, ICGV 95322, ICGV 95290) показывают высокий выход зерна. Имеется положительная соотносительность между выходом зерна и массой 1000 зерен (особенно у сортов ICGV 95322, ICGV 95248, Кыргызский местный, ICGV 95278, ICGV 95245).

Увеличение урожайности является главной целью большинства селекционных программ [8]. Данные по урожайности испытанных сортов показаны в табл. 2.

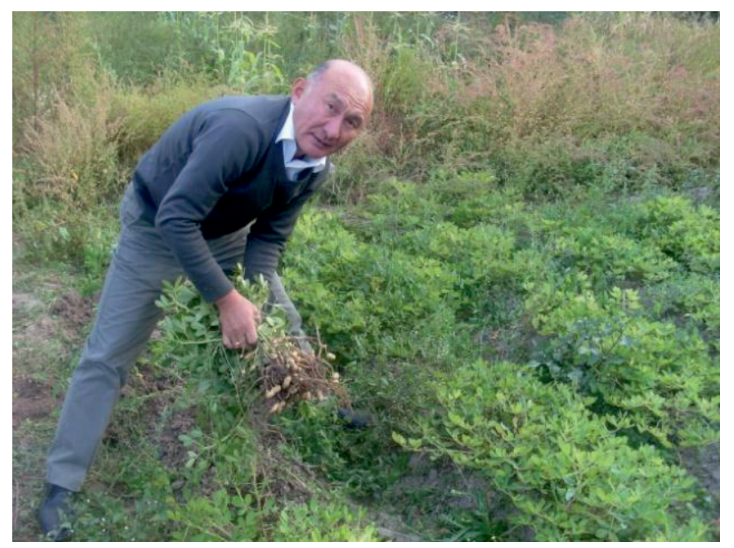

Pис. 2. Автор проводит оценку морфометрических показателей сортов арахиса 
Урожайность сортов арахиса за 2000-2002 гг.

Таблица 2

\begin{tabular}{|c|c|c|c|c|c|c|}
\hline \multirow{2}{*}{$\begin{array}{c}\text { № } \\
\Pi / \Pi\end{array}$} & \multirow[t]{2}{*}{ Сорта } & \multicolumn{4}{|c|}{ Урожайность по годам, кг/га } & \multirow{2}{*}{$\begin{array}{c}\text { Отклонения } \\
\text { от контроля } \\
(+),(-)\end{array}$} \\
\hline & & 2000 г. & 2001 г. & 2002 г. & Среднее & \\
\hline 1 & ICGV 94299 & 785 & 1108 & 930 & 943 & -1028 \\
\hline 2 & ICGV 94341 & 857 & 1212 & 1020 & 1029 & -942 \\
\hline 3 & ICGV 94350 & 895 & 1301 & 1240 & 1145 & -826 \\
\hline 4 & ICGV 94357 & 1095 & 1042 & 960 & 1032 & -939 \\
\hline 5 & ICGV 94358 & 1000 & 1100 & 890 & 990 & -981 \\
\hline 6 & ICGV 95244 & 1380 & 1684 & 1541 & 1535 & -436 \\
\hline 7 & ICGV 95245 & 900 & 1108 & 1001 & 1003 & -968 \\
\hline 8 & ICGV 95248 & 1452 & 1790 & 1609 & 1617 & -354 \\
\hline 9 & ICGV 95271 & 961 & 1165 & 1090 & 1072 & -899 \\
\hline 10 & ICGV 95278 & 1548 & 1641 & 1350 & 1513 & -458 \\
\hline 11 & ICGV 95290 & 2071 & 2192 & 2230 & 2164 & +193 \\
\hline 12 & ICGV 95299 & 952 & 1184 & 1080 & 1072 & -899 \\
\hline 13 & ICGV 95319 & 1214 & 1535 & 1320 & 1356 & -615 \\
\hline 14 & ICGV 95322 & 2112 & 2239 & 2080 & 2143 & +172 \\
\hline 15 & Chico & 1319 & 1637 & 1090 & 1348 & -623 \\
\hline 16 & $\begin{array}{c}\text { Кыргызский } \\
\text { местный (контроль) }\end{array}$ & 2100 & 1900 & 1915 & 1971 & - \\
\hline & Среднее & 1290 & 1489 & 1334 & 1371 & \\
\hline & $\mathrm{HCP}_{0,95}$, кг/га & 25 & 261 & 151 & 145,6 & \\
\hline & $\mathrm{S}_{\mathrm{x}} \%$ & 3,1 & 2,8 & 2,9 & 2,9 & \\
\hline
\end{tabular}

Данные таблицы показывают, что из испытанных сортов максимальную продуктивность показали два сорта ICGV 95290 и ICGV 95322, которые дали прибавку урожая зерна соответственно 193 и 172 кг с 1 га по сравнению с контрольным сортом - Кыргызский местный. Наименьшая урожайность зерна получена от сорта ICGV 94299.

\section{Заключение}

Из испытанных сортов международной коллекции арахиса (ICGV - International Collection Groundnut Varieties) по своим морфометрическим и продуктивным показателям наилучшие результаты получены у сортов ICGV 95290, ICGV 95322. Их следует использовать на производстве для получения высоких урожаев зерна, улучшения питания, обеспечения продовольственной безопасности в стране.

\section{Список литературы}

1. UN Food Food and Agriculture Organization // Production of groundnut by countries [Электронный ресурс]. - Режим доступа: http://faostat.fao.org/site/567/default.aspx\#ancor (дата обращения: 17.01.18).

2. Ntare B.R., Diallo A.T., Ndjeunga J., Waliyar F. Groundnut seed production manual // ICRISAT, FAO. $-2006 .-20$ p.

3. Nigam S.N., Rao V. Ramanatha, Gibbons R.W. Utilization of natural hybrids in the improvement of ground- nuts (Arachis hypogaea)// Expl. Agric. - 1983. - Vol. 19. P. 355-359.

4. Putnam D.H., Oplinger E.S., Teynor T.M., Oelke E.A., Kelling K.A., Doll J.D. Peanut [Электронный pecypc]. - Peжим доступа: http://corn.agronomy.wisc.edu/Crops/Peanut. aspx (дата обращения: 17.01.18).

5. Singh A.L., Hariprassana K., Solanki R.M. Screening and selection of groundnut genotypes for tolerance of soil salinity // Australian Journal of Crop Science. - 2008. - Vol. 1. P. 69-77.

6. Howlader S.H., Bashar H.M.K., Islam M.S., Mamun M.H., Jahan S.M.H. Effect of plant spacings on the yield and yield attributes of groundnut // International Journal Sustainable Crop Production. - 2009. - Vol. 4. - P. 41-44.

7. Bala N.M.B., Ogunlela V.B., Tanima B., Kuchinda N.C. Response of two groundnut (Arachis hypogaea L.) varieties to sowing date and NPK fertilizer rate in a Semi-Arid environment: growth and growth attributes // Asian Journal of Crop Science. 2011. - Vol. 3. - P. 141-150.

8. Mohamed H.A., Clark J.A., Ong C.K. Genotypic differences in the temperature responses of tropical crops. I. Germination characteristics of groundnut (Arachis hypogaea L.) and pearl-millet (Pennisetum typhoides S \& L.) // J. Exp. Bot. 1988. - Vol. 39. - P. 1121-1128.

9. Асаналиев А.Ж., Султанбаева В.А., Хегай С.В., Содомбеков И. Продуктивность нута в зависимости от сроков и схем посева в предгорной зоне Чуйской долины // Успехи современного естествознания. - 2017. - № 3. - С. 46-50.

10. Kerridge C.P. Biology and agronomy of Arachis // CIAT. - 1994. - Vol. 240

\section{References}

1. UN Food Food and Agriculture Organization // Production of groundnut by countries [Jelektronnyj resurs]. Rezhim 
dostupa: http://faostat.fao.org/site/567/default.aspx\#ancor (data obrashhenija: 17.01.18).

2. Ntare B.R., Diallo A.T., Ndjeunga J., Waliyar F. Groundnut seed production manual // ICRISAT, FAO. 2006. 20 p.

3. Nigam S.N., Rao V. Ramanatha, Gibbons R.W. Utilization of natural hybrids in the improvement of groundnuts (Arachis hypogaea)// Expl. Agric. 1983. Vol. 19. pp. 355-359.

4. Putnam D.H., Oplinger E.S., Teynor T.M., Oelke E.A. Kelling K.A., Doll J.D. Peanut [Jelektronnyj resurs]. Rezhim dostupa: http://corn.agronomy.wisc.edu/Crops/Peanut.aspx (data obrashhenija: 17.01.18)

5. Singh A.L., Hariprassana K., Solanki R.M. Screening and selection of groundnut genotypes for tolerance of soil salinity // Australian Journal of Crop Science. 2008. Vol. 1. pp. 69-77.

6. Howlader S.H., Bashar H.M.K., Islam M.S., Mamun M.H., Jahan S.M.H. Effect of plant spacings on the yield and yield attributes of groundnut // International Journal Sustainable Crop Production. 2009. Vol. 4. pp. 41-44.

7. Bala N.M.B., Ogunlela V.B., Tanima B., Kuchinda N.C. Response of two groundnut (Arachis hypogaea L.) varieties to sowing date and NPK fertilizer rate in a Semi-Arid environment: growth and growth attributes // Asian Journal of Crop Science. 2011. Vol. 3. pp. 141-150.

8. Mohamed H.A., Clark J.A., Ong C.K. Genotypic differences in the temperature responses of tropical crops. I. Germination characteristics of groundnut (Arachis hypogaea L.) and pearl-millet (Pennisetum typhoides S \& L.) // J. Exp. Bot. 1988. Vol. 39. pp. 1121-1128.

9. Asanaliev A.Zh., Sultanbaeva V.A., Hegaj S.V., Sodombekov I. Produktivnost nuta v zavisimosti ot srokov i shem poseva v predgornoj zone Chujskoj doliny // Uspehi sovremennogo estestvoznanija. 2017. no. 3. pp. 46-50.

10. Kerridge C.P. Biology and agronomy of Arachis // CIAT. 1994. Vol. 240 